\title{
PROMOÇÃO DO CONSUMO DE PLANTAS ALIMENTÍCIAS NÃO CONVENCIONAIS (PANC) COM CRIANÇAS EM SITUAÇÃO DE VULNERABILIDADE SOCIAL EM SANTA CRUZ DO SUL (RS)
}

Raquel Figueiredo De Oliveira ${ }^{1}$

Fernanda Ludwig²

Resumo: $O$ presente trabalho foi conduzido com o objetivo de desenvolver estratégias de promoção da importância e utilização das Plantas Alimentícias Não Convencionais (PANC) e de uma alimentação saudável com crianças em vulnerabilidade social na cidade de Santa Cruz do Sul/ RS. As atividades foram realizadas durante 4 encontros com crianças em idade de 5 a 11 anos. Para reconhecimento e avaliação da turma, foi aplicado um questionário semiestruturado pré-intervenção e outro pós-intervenção e realizadas duas oficinas; uma com apresentação de slides sobre o tema e outra com atividades práticas de plantio e experimentação de receita utilizando PANC. A partir dos resultados obtidos conclui-se que as ações realizadas junto com crianças em vulnerabilidade social foram efetivas na promoção e valorização das PANC e da alimentação saudável.

Palavras-chave: PANC; Alimentação Saudável; Alimentos Orgânicos.

Abstract: The present work was carried out with the objective of developing strategies to promote the importance and use of Unconventional Food Plants (PANC) and healthy eating with children in social vulnerability in the city of Santa Cruz do Sul / RS. The activities were carried out during 4 meetings with children aged 5 to 11 years. For the recognition and evaluation of the class, a preintervention and a post-intervention semi-structured questionnaire was applied, and two workshops were held; one with a slide show on the topic and the other with practical planting activities and experimenting with recipes using PANC. From the results obtained, it is concluded that the actions carried out with socially vulnerable children were effective in promoting and valuing PANC and healthy eating.

Keywords: PANC; Healthy Eating. Organic Food.

1 Universidade Estadual do Rio Grande do Sul / UERGS. E-mail: figueiredoraq@gmail.com.

Link para o Lattes: http://lattes.cnpq.br/1206213196211689

2 Universidade Estadual do Rio Grande do Sul / UERGS. E-mail: fernanda-ludwig@uergs.edu.br. Link para o Lattes: http://lattes.cnpq.br/8424320302435211 


\section{Introdução}

A concepção de vulnerabilidade social não se restringe somente à situação de pobreza, mas está associada a um conjunto de circunstâncias, como desemprego, dificuldades de inserção social, enfermidades e violência, interligada também às fragilidades de vínculos afetivo-relacionais e desigualdade de acesso a bens e serviços públicos (CANÇADO et al., 2014; BRASIL, 2004).

De forma geral, as vulnerabilidades das crianças, adolescentes e de suas famílias manifestam-se em violência cotidiana no contexto familiar e escolar. A falta de oferta de uma educação de qualidade, os baixos salários e o desemprego afetam também a trajetória de vida desses brasileiros, obrigandoos a se inserirem precocemente no mercado de trabalho e/ou no tráfico de drogas (FONSECA et al., 2013 p. 260).

Sendo assim, crianças inseridas em um contexto de vulnerabilidade social possuem menores condições socioeconômicas, o que causa impacto na qualidade de vida, por não ter acesso garantido a uma alimentação permanente e de qualidade, resultando em insegurança e redução da soberania alimentar (SOUZA et al., 2019; VIEIRA et al., 2006). Nesse contexto, o acesso a alimentos industrializados torna-se mais fácil, visto que muitas destas famílias passam mais tempo na jornada de trabalho e se dedicam menos ao preparo de suas refeições. Assim, optam pela facilidade conferida pelos produtos embalados e pré-prontos, mesmo que isso signifique menos nutrientes, mais açúcares e gorduras, resultando em problemas de saúde (COSTA et al., 2018; GIRALDI, 2012).

Aliado à industrialização dos alimentos, o uso de agrotóxicos nos sistemas de produção tem sido relacionado à contaminação alimentar e doenças (DUTRA; DE SOUZA, 2017). Por outro lado, os produtos orgânicos vêm ganhando reconhecimento como elementos potencialmente capazes de melhorar a qualidade alimentar de muitas famílias rurais e urbanas, apresentam um diferencial para quem busca qualidade, segurança e responsabilidade ambiental e alimentar (PAULA FILHO, 2015).

Somado aos benefícios dos alimentos orgânicos, atualmente, as Plantas Alimentícias Não Convencionais, ou PANC, vem ganhando destaque pela sua rusticidade e adaptação à diferentes ambientes, muitas delas com crescimento espontâneo. As PANC são representadas por espécies comestíveis nativas, exóticas, espontâneas, silvestres ou domesticadas que não fazem parte da cadeia produtiva e da dieta habitual de uma parcela da população, englobando também partes não usuais de plantas conhecidas com potencial alimentício (KINUPP; LORENZI, 2014). Estas plantas são adaptadas ao clima, ao solo brasileiro e às diferentes estações do ano, de maneira que não dependem de insumos. Além disso, são alimentos ricos em nutrientes (KINUPP; BARROS, 2007). Neste caso, a produção e o consumo das PANC pode ser uma estratégia para a diversificação alimentar, assumindo o papel social de fortalecer a soberania alimentar e nutricional de agricultores e consumidores. 
O Brasil é um país rico em biodiversidade, e as PANC fazem parte desta diversidade, podendo complementar o cardápio como fonte de alimento saudável e nutritivo. Ainda assim, muitas vezes são esquecidas ou negligenciadas (BORGES; SILVA, 2018). Segundo Kinupp e Barros (2007), na região metropolitana de Porto Alegre foram encontradas 312 espécies de plantas alimentícias nativas, estimando ainda que $10 \%$ da flora nativa do Brasil seja alimentícia. No entanto, a alimentação de grande parte da população está baseada em uma pequena parcela de alimentos, sendo que $90 \%$ dos alimentos consumidos vêm somente de 20 tipos de plantas (KELEN et al., 2015).

As PANC são ricas em nutrientes, fibras e compostos com funções antioxidantes, geralmente apresentam teores de minerais e proteínas significativamente maiores do que as plantas domesticadas e contribuem muito para ampliar a variedade nutricional do cardápio diário, incrementando diversos pratos (KINUPP; BARROS, 2008). A casca da banana é considerada uma PANC, por ser uma parte alimentícia não convencional e não ser habitualmente consumida. Ainda assim, é rica em nutrientes e fibras, e pode apresentar quantidades de Vitamina C e fibras maiores que a sua polpa (GONDIM et al., 2005).

Outra PANC de destaque é a capuchinha (Tropaeolum majus), mais reconhecida pelas suas flores comestíveis, com folhas e flores de sabor picante, que podem ser consumidas cruas em saladas, sanduiches ou em receitas como mexidos de ovos e como tempero de maionese, molho branco e salpicão. É rica em ferro, vitamina $C$, sais minerais e por isso é considerada uma hortaliça nutritiva (SANGALLI et al., 2007; CASTRO; DEVIDE, 2016; RANIERI et al., 2017). Suas flores coloridas têm um sabor de agrião e além da vitamina $C$, são ricas em substâncias antioxidantes e carotenoides que combatem os radicais livres (CASTRO; DEVIDE, 2016; RANIERI et al., 2017).

Para Wiggers et al. (2018), é importante o incentivo ao desenvolvimento de hábitos alimentares corretos e saudáveis com crianças, pois elas ainda estão desenvolvendo suas preferências alimentares, de modo que possuem melhor apropriação do que é lhes passado. E a escola é o local onde ocorrem as discussões referente a hábitos alimentares e como estes podem influenciar na saúde.

Sendo assim, o presente trabalho foi conduzido com o objetivo de desenvolver estratégias de promoção da importância e utilização das PANC e de uma alimentação saudável com crianças em vulnerabilidade social na cidade de Santa Cruz do Sul/ RS.

\section{Material e Métodos}

\section{Contexto e sujeitos da pesquisa}

O presente trabalho foi realizado no mês de setembro de 2019, com uma turma de 10 crianças em idade de 5 a 11 anos, que frequentam o Projeto Social. Este projeto iniciou suas atividades em 2009, tendo sua sede localizada em área urbana na cidade de Santa Cruz do Sul/RS, onde atende crianças em 
vulnerabilidade social. Atualmente, possui duas monitoras em tempo integral e voluntários que desenvolvem, com as crianças, atividades no turno inverso da escola. Além de proporcionar um local para as crianças brincarem, oferece também alimentação, cuidado, oficinas de inglês, reciclagem, leitura e o desenvolvimento de princípios cristãos.

O projeto atualmente, atende cerca de 40 crianças. No turno da manhã, momento em que foi realizado o trabalho, 20 crianças encontram-se matriculadas, no entanto, não são assíduas ao projeto. Durante as atividades da pesquisa ação apenas 10 crianças participaram de todas as etapas. Por isso, foram avaliadas as respostas de 10 crianças que participaram da pesquisa, destas duas eram meninas e oito eram meninos. Dessa forma, a pesquisa foi realizada com um subgrupo típico em relação ao total da população de crianças, determinada como amostragem por tipicidade (MARCONI; LAKATOS, 2018), sendo descritas as respostas e comentários do grupo que participou da pesquisa (GIL, 2008). As atividades seguiram o delineamento experimental da pesquisa-ação proposta por Thiollent (1986), por sua capacidade de agregar métodos e estratégias baseados na participação ativa de pesquisadores e atores sociais em busca da resolução de problemas.

As atividades da pesquisa foram concentradas nos dias 10/09 (1은

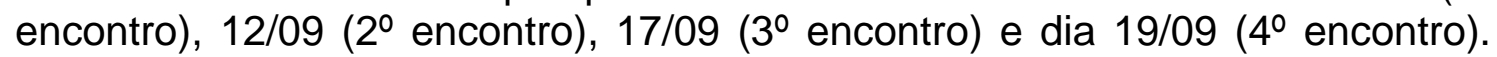
Os participantes da turma da manhã foram submetidos a dois momentos de avaliação; um antes de se iniciar o programa - avaliação pré-intervenção; e outro após, avaliação pós-intervenção, por meio de um questionário semiestruturado (ANEXO A). O questionário pré-intervenção possuía questões sobre hábitos alimentares e sobre o conhecimento referente às Plantas Alimentícias Não Convencionais (PANC). O questionário pós-intervenção possuía as mesmas questões do primeiro questionário, porém apenas relacionado ao conhecimento sobre PANC e alimentação orgânica.

\section{Intervenção}

\section{Oficina 1: Conhecimento prévio e diálogo inicial sobre PANC}

No primeiro encontro, foi entregue às crianças o questionário préintervenção, para ser preenchido enquanto estavam no local do projeto, sendo orientadas quanto ao preenchimento e quanto às dúvidas que surgiam.

Posteriormente, os estudantes provaram um bolo feito de casca de banana, preparado anteriormente, de modo que eles não sabiam qual era o ingrediente principal da receita.

\section{Avaliação da oficina}

Depois de provarem o bolo feito de casca de banana, as crianças responderam ao teste de aceitabilidade usando a escala hedônica facial de 5 pontos (Figura 1), na qual foram usadas figuras para expressar a aceitação do 
alimento, sendo elas: 1- Detestei; 2- Não gostei; 3- Indiferente; 4- Gostei e 5Adorei (CECANE, 2010). Após, foi realizada uma conversa sobre o bolo e se eles tinham sugestões sobre qual seria o ingrediente principal dele.

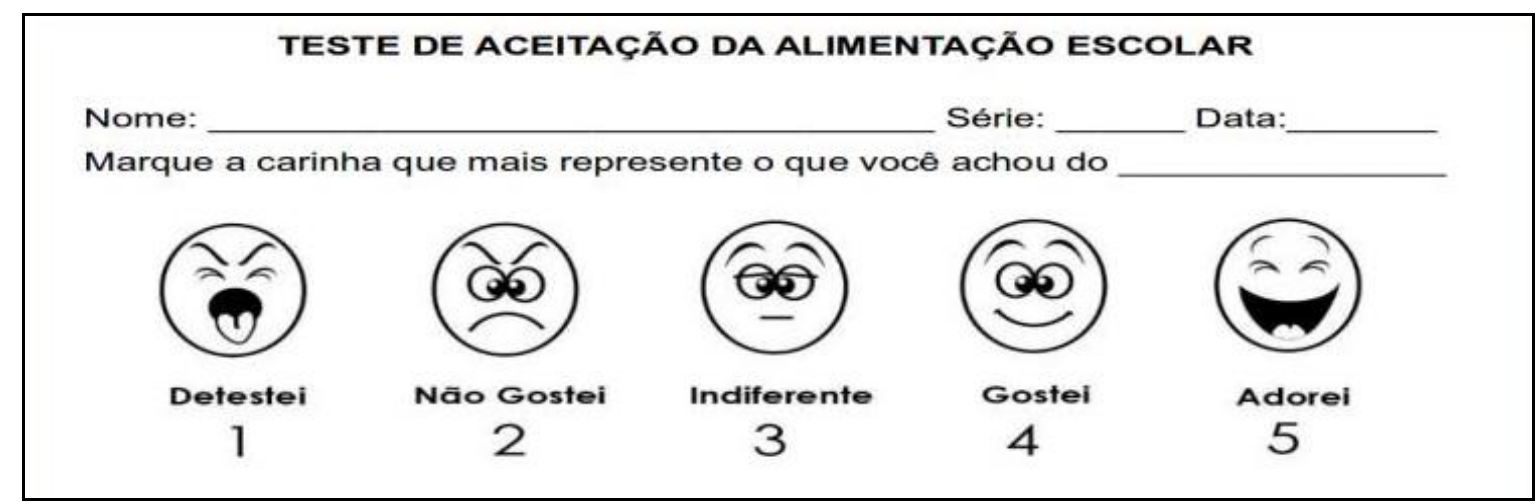

Figura 1: Modelo de ficha para aplicação de escala hedônica facial.

Fonte: CECANE, 2010.

\section{Oficina 2: Diálogos diversificados}

No segundo encontro, ocorrido na semana seguinte, foi realizada uma oficina abordando temas vistos no questionário, como a alimentação saudável, através da discussão sobre a pirâmide alimentar, produtos orgânicos e PANC. Foram apresentadas fotos em slides de algumas PANC, tais como ora-pronobis (Pereskia aculeata), peixinho-de-jardim (Stachys byzantina), capuchinha (Tropaeolum majus) e partes alimentícias não convencionais, como a folha de batata-doce e o coração de bananeira. Por meio de uma conversa informal, foram discutidos os conhecimentos sobre as PANC e sua importância.

\section{Oficina 3: Plantio e utilização da capuchinha (Tropaeolum majus)}

No terceiro encontro, as crianças foram divididas em cinco grupos, e cada grupo realizou o plantio de mudas de capuchinha em recipientes de material reciclado. Foram utilizadas garrafas PET previamente cortadas, as quais foram preenchidas com substrato para realização do plantio, pelos alunos. Neste momento, discutiu-se sobre os cuidados necessários com as plantas, que elas precisam de atenção, de sol, água e que a capuchinha possui como característica a adaptação a diferentes condições climáticas. Além disso, foram apresentadas as partes comestíveis, e os alunos fizeram a colheita das flores e folhas, e realizada a higienização antes de experimentá-las. As plantas permaneceram no local do projeto, sendo que cada grupo ficou responsável por cuidar de sua muda. Posteriormente, flores e folhas de capuchinha foram incluídas no lanche, podendo ser experimentada pura (flor) e junto com sanduíche, banana ou como preferissem (folha). 


\section{Avaliação da oficina}

$\mathrm{Na}$ sequência, as crianças responderam ao teste de aceitabilidade usando a escala hedônica facial de 5 pontos (Fig.1).

\section{Oficina 4: Avaliação dos conhecimentos pós - intervenção}

No quarto encontro, os alunos responderam o questionário pósintervenção, durante o período que estavam no local do projeto, sendo orientados também durante o preenchimento e quanto as possíveis dúvidas.

\section{Análise dos dados}

Os dados obtidos foram organizados e tabulados, construindo-se gráficos comparativos entre os resultados obtidos com os questionários pré e pós-intervenção, indicados com valores percentuais, utilizando o editor de planilhas Microsoft Office Excel. Foram analisadas também as observações e os relatos dos alunos referentes aos assuntos trabalhados.

\section{Resultados e Discussões}

\section{Hábitos alimentares}

Os resultados apresentados pelos participantes indicam que todos realizam as três refeições principais (café-da-manhã, almoço e janta) e apenas dois não comem frutas diariamente. As frutas mais citadas quanto a preferência foram: maçã, banana, melancia, morango, laranja e uva (Figura 2).

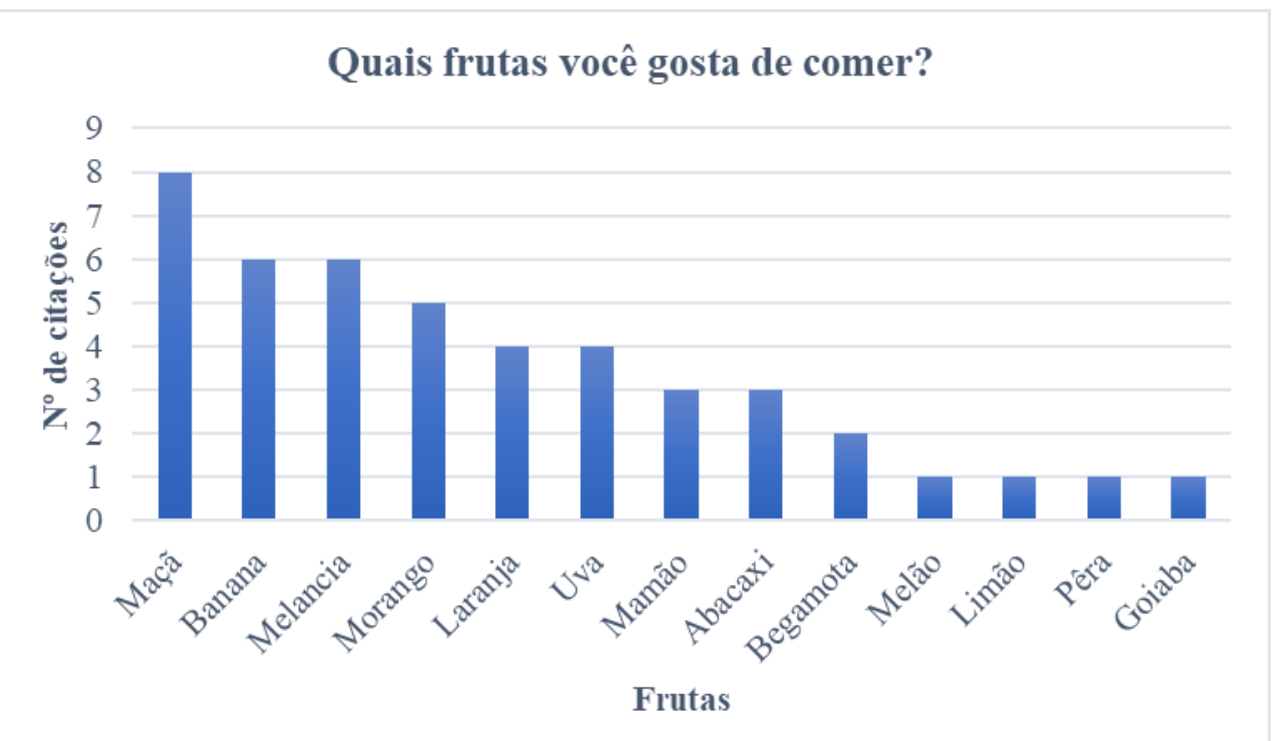

Figura 2: Frutas citadas como preferidas pelas crianças participantes da pesquisa. Santa Cruz do Sul/RS, 2019.

Fonte: Autor, 2019. 
Quanto ao consumo de hortaliças, quatro crianças consomem de quatro a menos vezes por semana e seis raramente consomem. Das hortaliças mais mencionadas está o tomate e a alface, sendo citada quatro vezes cada, como a que mais gostam de comer. No entanto, cinco crianças não citaram hortaliças que possuem preferência, pois não gostam (Figura 3).

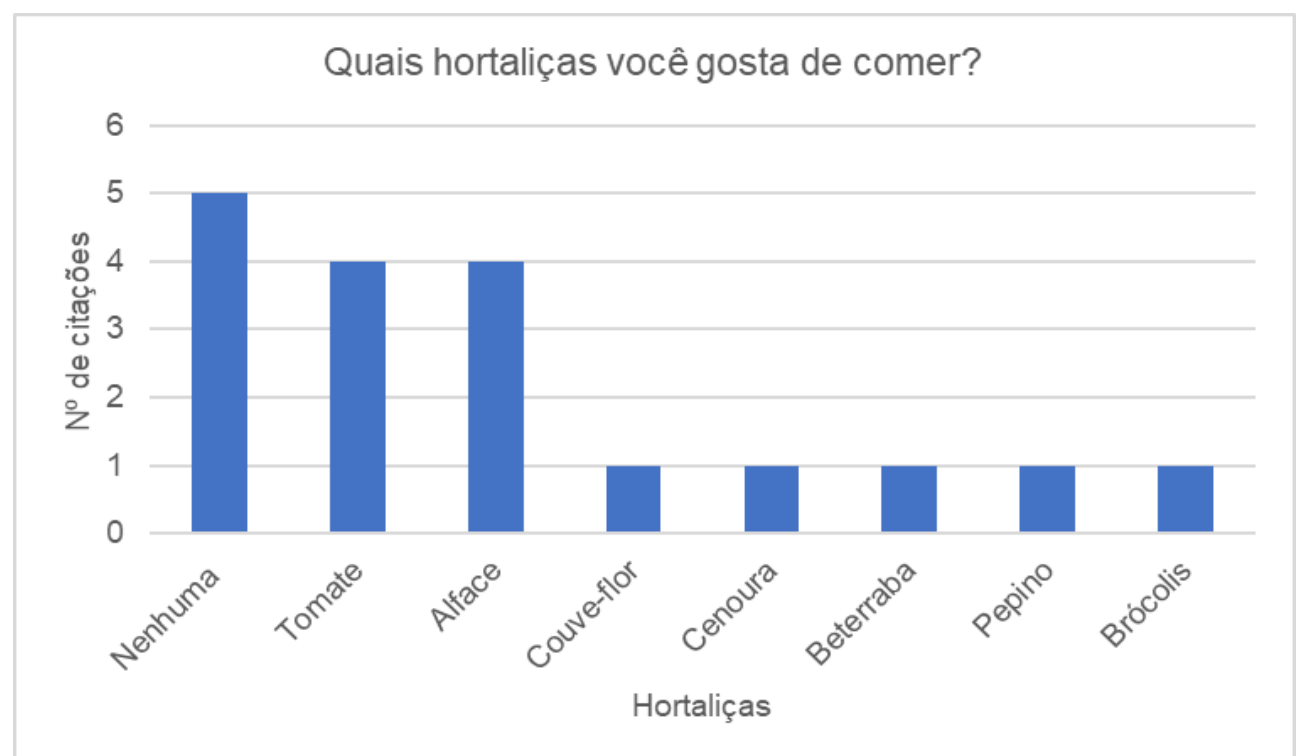

Figura 3: Hortaliças citadas como preferidas pelas crianças participantes da pesquisa. Santa Cruz do Sul/RS, 2019.

Fonte: Autor, 2019.

Castelo Branco et al. (2006), ao realizar o levantamento do perfil de consumidores de hortaliças, constataram que as mais consumidas eram alface, tomate e cenoura, sendo que o consumo de tomate variava de acordo com o preço. Em outras pesquisas, o tomate e a alface foram as hortaliças mais citadas quanto ao consumo e frequência, sendo que muitos justificam a escolha por essas hortaliças possuírem boa aparência, serem agradáveis ao paladar, e estarem disponíveis nas feiras (DE SOUZA et al., 2008, VIEBIG et al., 2009, SOUZA et al., 2013, FRANCILINO et al., 2014).

Apenas um dos participantes possui o hábito de tomar refrigerante todos os dias os outros tomam refrigerante apenas nos finais de semana. O mesmo ocorre com o consumo de lanches como cachorro-quente e xis-burguer, sendo que apenas dois não comem, e os outros comem apenas no final de semana. Apesar de terem acesso a frutas e hortaliças, muitos relataram: "gosto de comer batata-frita, é melhor do que comer salada", enquanto outros comentaram: "batata-frita não é saudável, não podemos comer todos os dias".

Quando questionados sobre o que é alimentação saudável, dois não sabiam responder, dois responderam que "é ter uma alimentação balanceada" e seis responderam que era "verduras e frutas". Durante a oficina, ao ser mostrada e discutida a pirâmide alimentar, os estudantes disseram já ter visto a 
mesma e sabiam que esta ilustrava como deveria ser uma alimentação saudável. Uma das falas ao ver a pirâmide e associar a alimentação saudável foi: "é não comer muitas frituras e doces e mais saladas, carne, arroz e feijão".

As crianças que participaram da pesquisa possuem o hábito de comer frutas, mas não possuem o hábito de comer hortaliças com frequência. De acordo com as monitoras do projeto, durante o lanche são disponibilizadas frutas para consumo, o que pode ter influenciado em uma maior frequência do consumo destes alimentos, visto que eles não realizam refeições utilizando hortaliças enquanto estão no projeto. Birch et al. (2007) defendem que o comportamento alimentar das crianças é influenciado pelos fatores fisiológicos, como a experiência com os alimentos, mas também por fatores ambientais, como a observação de modelos (família/pais), pela escola, pela rede social, pelas propagandas da mídia e pelas condições socioeconômicas durante a infância.

Durante o desenvolvimento da pesquisa, foram trabalhados os conhecimentos referentes à alimentação saudável, porém sem focar diretamente na mudança de hábitos alimentares. Contudo, pode-se constatar, a partir das respostas sobre à alimentação saudável, que os alunos do projeto possuem o conhecimento sobre o assunto. De Almeida et. al. (2013) ressaltam que é importante trabalhar com as crianças, conteúdos relacionados a alimentação e nutrição saudável, pois estas questões irão refletir na vida das pessoas que convivem com os alunos. Uma alimentação saudável e equilibrada, promovendo o consumo de frutas, hortaliças e alimentos ricos em nutrientes, faz com que a criança desenvolva hábitos saudáveis que podem levar para a vida toda. Na escola, pode ser incentivada a mudança de hábitos e discutida a importância de uma alimentação saudável, mas o incentivo por parte dos pais, com a família, é muito importante, pois a oferta de alimentos saudáveis na infância torna mais provável que as escolhas saudáveis persistam ao longo da vida (OTT et al., 2014).

\section{Alimentação orgânica}

Sobre a alimentação orgânica, apenas dois responderam o que achavam que era, um respondeu "porcaria?" e outro "é uma alimentação que tem alimentos orgânicos", mas não sabia dar exemplo ou desenvolver melhor sua resposta, mostrando que realmente não conheciam o tema. Durante a oficina, foi mostrado o slide de um homem colocando agrotóxico na plantação, e quando questionados se eles sabiam o que o homem estava fazendo, as respostas foram: "tá colocando veneno", "não faz bem comer salada que colocaram veneno" e "precisa lavar bem antes de comer". Depois, foi mostrado um slide de uma família cuidando da plantação, ao olhar a imagem, foi questionado o que eles percebiam nas imagens, e eles relataram: "toda a família trabalhando junto" e, "eles estão capinando e não estão colocando veneno". Posteriormente, foi explicado sobre a produção de alimentos sem usar agrotóxico. 
Apesar dos alunos não terem conhecimento sobre os temas "alimento convencional" ou "orgânico", eles souberam reconhecer as práticas que diferenciam os dois tipos de cultivo. De acordo com Sousa (2009), realizar a discussão sobre esses conceitos possibilita que as crianças adquiram novas experiências e aprendizagens, que poderão, posteriormente, ser compartilhados em casa.

No questionário realizado depois das oficinas, apenas dois responderam que não lembravam o que era alimentação orgânica os demais responderam: "alimento sem agrotóxico"; "uma alimentação sem veneno". Sendo assim, de maneira geral, eles lembraram o significado de uma alimentação orgânica, a qual se baseia em uma produção livre de contaminantes, saudável e sustentável, preocupada com o consumidor e com o meio ambiente (ALVES; CUNHA, 2012; DIAS et al., 2015). Além disso, para Darolt (2007), consumir alimentos orgânicos faz parte de uma alimentação saudável, sendo que, os alimentos orgânicos são aqueles que não utilizam insumos na produção, de modo que não prejudicam o meio ambiente, os agricultores e os consumidores, com substâncias químicas nocivas.

\section{Aceitabilidade e PANC}

O bolo elaborado com casca de banana foi provado por todos; ao ser analisado o questionáro de aceitabilidade, foi possível constatar que $40 \%$ dos estudantes responderam "adorei", 40\% responderam "gostei", e 20\% responderam "indiferente" e nenhum dos deles respondeu "não gostei" ou "detestei" (Figura $4)$.

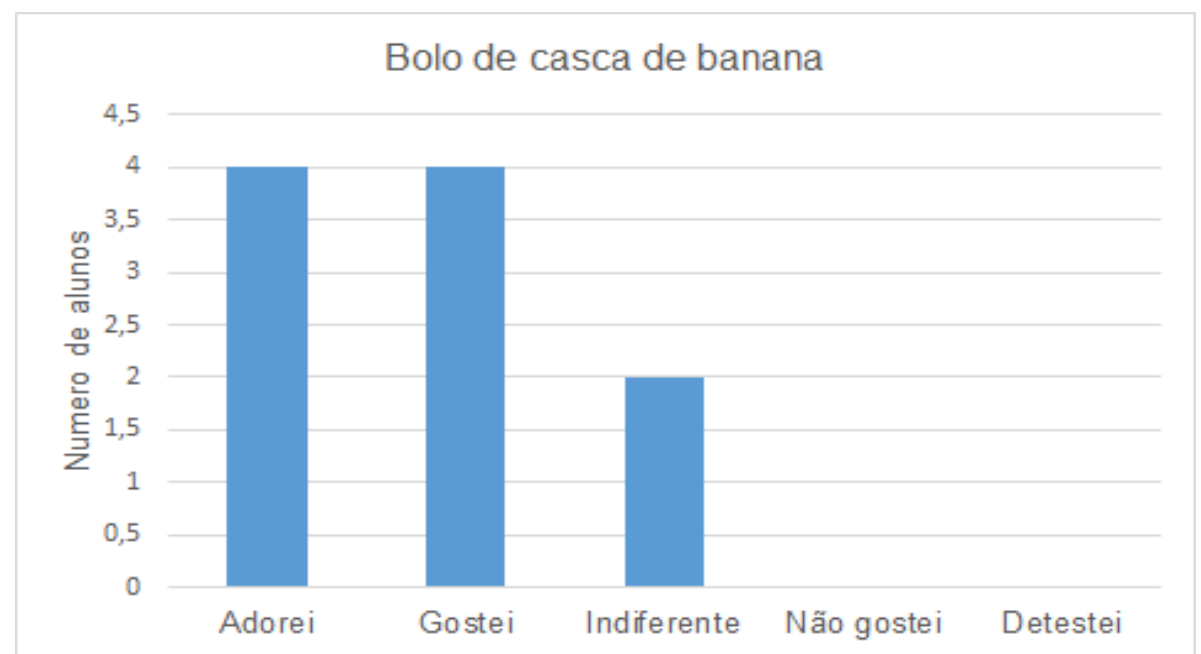

Figura 4: Teste de aceitabilidade do bolo de casca de banana pelas crianças participantes da pesquisa. Santa Cruz do Sul/RS, 2019.

Fonte: Autor, 2019.

O bolo de casca de banana teve uma boa aceitação por todos. Após a experimentação, realizou-se uma conversa informal sobre o bolo e a percepção de cada um. Eles foram questionados sobre o sabor e quais os ingredientes 
acreditavam ter no bolo. Durante a conversa, três sugeriram que ele era feito de banana. Os relatos foram: "tem gosto de banana" e, "achei parecido com o gosto de cuca de banana". Quando souberam que era feito de casca de banana, ficaram surpresos. Nenhum deles tinha comido bolo de casca de banana, mas responderam que comeriam novamente. Alguns alunos compartilharam: "acho que se tu tivesse dito que era de casca de banana, eu não teria experimentado, mas gostei", "ele ficou bom, comeria de novo", "achei que faltou a cobertura de chocolate, mas estava muito bom". A casca da banana também é conhecida como PANC, sendo rica em nutrientes. No entanto, muitas vezes não faz parte das receitas por falta de informação e conhecimento dos seus benefícios e das formas corretas de preparo (RAIMUNDO et al., 2018).

A população, em geral, apresenta resistência ao uso de produtos e subprodutos, como cascas e talos, que poderiam ajudar a suprir as necessidades nutricionais e diminuir o desperdício; realizar a análise sensorial de receitas que utilizam subprodutos é uma forma de analisar a aceitabilidade quanto à utilização de cascas, por exemplo. Nunes (2009), realizou um estudo com alunos de 17 a 45 anos sobre a aceitação de bolo de banana sem a casca, encontrou $94 \%$ de aceitação. Desta forma, é possível verificar que um bolo preparado com a casca da banana possui boa aceitabilidade, assim como um bolo utilizando a banana de forma convencional. Em estudo semelhante, realizado com a população que frequenta um Restaurante Corporativo, Aiolfi e Basso (2016) constataram uma aceitabilidade de $98,8 \%$ para o bolo de banana com casca, o que demonstra que o uso integral de alimentos é bem aceito nas preparações.

No questionário pré-intervenção, $60 \%$ responderam não conhecer as PANC, e outros $40 \%$ responderam que talvez soubessem (Figura 5).

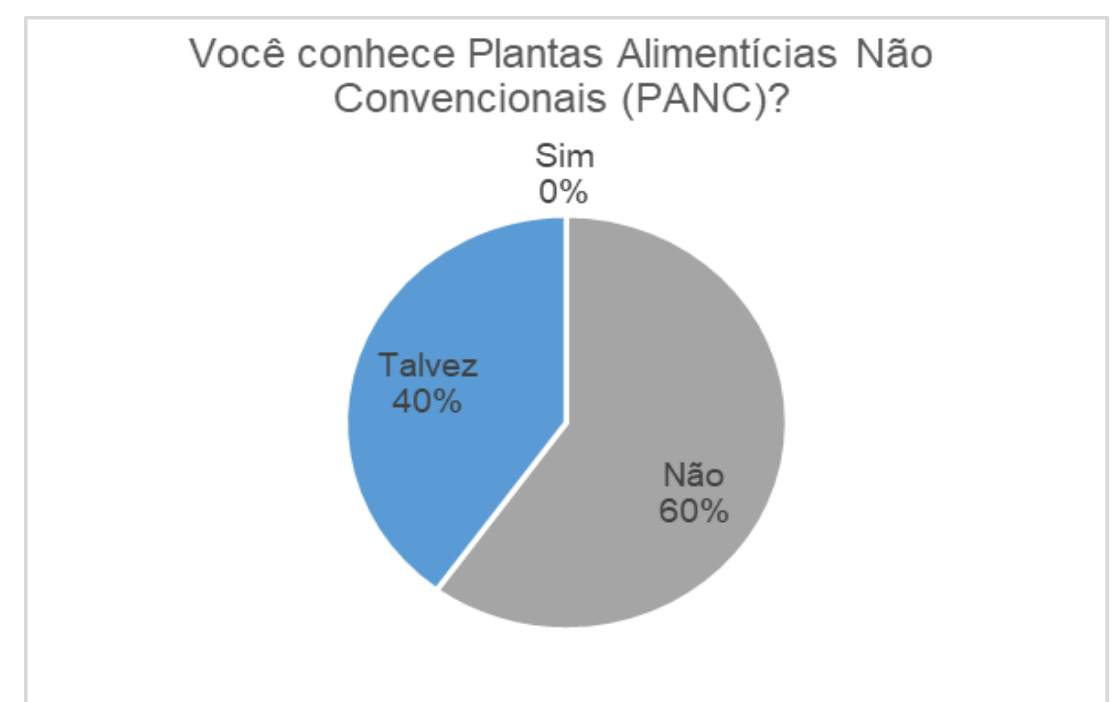

Figura 5: Conhecimento sobre o termo PANC pelas crianças participantes da pesquisa, anteriormente à intervenção. Santa Cruz do Sul/RS, 2019.

Fonte: Autor, 2019. 
Quando estes foram questionados sobre o que era o termo "PANC", dois não souberam responder e dois responderam: "pão"; "arroz, feijão e carne de gado", mostrando assim que realmente desconheciam o significado da palavra. Em seu trabalho, Borges e Silva (2018) também constataram que a compreensão sobre as PANC ainda é bastante abstrata, por isso a adesão destas plantas na alimentação é bastante limitada.

Durante a oficina, todos se mostraram curiosos e interessados sobre o tema, momento em que foi discutido o conceito de PANC e que elas são representadas por espécies comestíveis nativas, exóticas, espontâneas, silvestres ou domesticadas que não fazem parte da cadeia produtiva e da dieta habitual de uma parcela da população, englobando também partes não usuais de plantas conhecidas com potencial alimentício (KINUPP; LORENZI, 2014).

No questionário pós-intervenção, todos demonstraram conhecer o termo PANC. No entanto, $80 \%$ sabiam o que significava o termo e $20 \%$ ficaram em dúvida se lembravam (Figura 6).

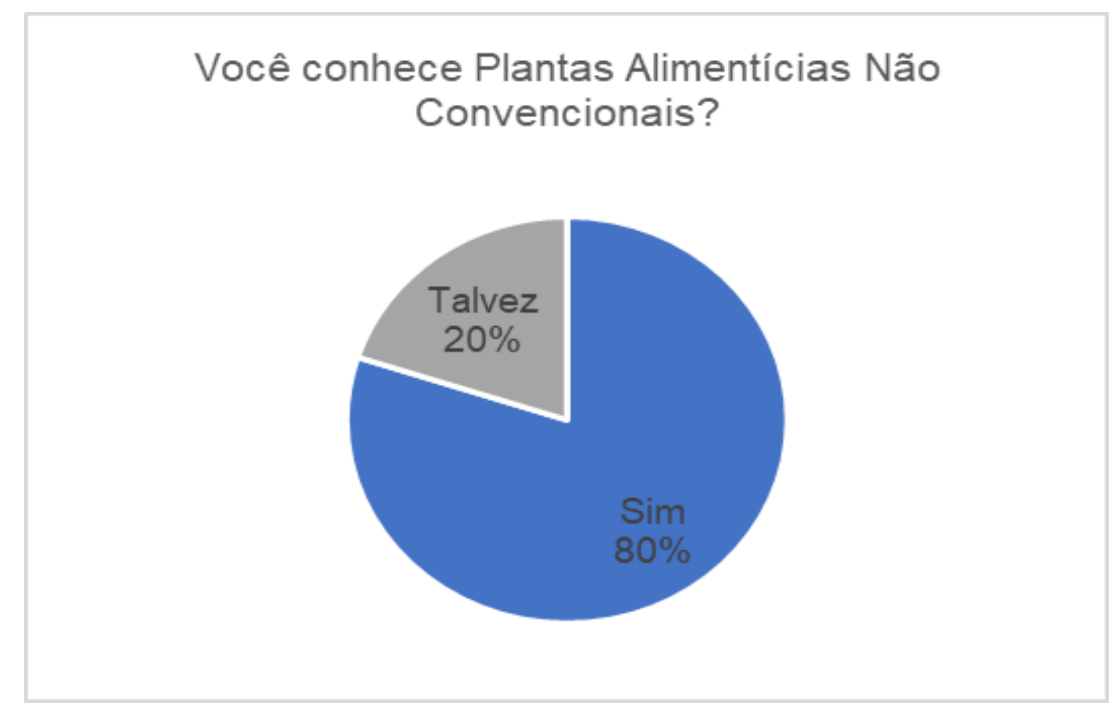

Figura 6: Conhecimento sobre o termo PANC pelas crianças participantes da pesquisa, posteriormente à intervenção. Santa Cruz do Sul/RS, 2019.

Fonte: Autor, 2019.

Durante a atividade de plantio das mudas de capuchinha, todos participaram ativamente e contribuíram para que seu grupo realizasse a tarefa com cuidado e empenho. Ter colocado a "mão na terra" e conhecido a capuchinha, fez com que eles tivessem mais interesse em experimentá-la. Antes da oficina, nenhuma criança havia experimentado, nem a conheciam como sendo uma PANC. Porém, depois de conhecer e fazer o plantio, todas optaram por experimentar, sendo que a flor foi apreciada por todos. No entanto, um dos estudantes preferiu não experimentar a folha. 
No questionário de aceitabilidade, nenhum dos alunos respondeu "detestei" ou "não gostei", mostrando a boa aceitabilidade desta PANC (Figura 7).

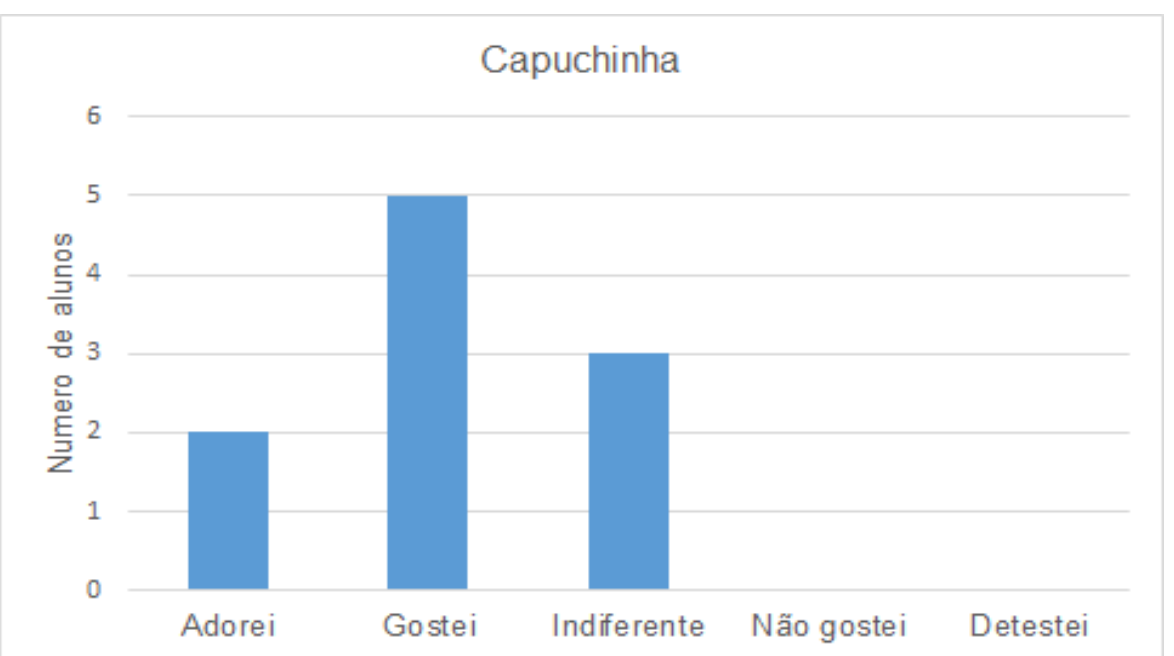

Figura 7: Teste de aceitabilidade da capuchinha pelas crianças participantes da pesquisa. Santa Cruz do Sul/RS, 2019.

Fonte: Autor, 2019.

No momento de provar a capuchinha, as crianças apenas receberam a orientação de experimentarem a folha dela junto com o pão, ou com algum outro alimento, e que a folha poderia substituir a alface do sanduíche. Uma das alunas teve a ideia de comer com a banana e gostou. Todos optaram por comer a flor pura, a qual teve uma aceitação tão grande, a ponto de pedirem mais.

Golze e Souza (2009), ao realizarem estudo sobre a aceitabilidade de adultos, quanto à pratos elaborados com base na capuchinha, encontraram $100 \%$ de aceitação, sendo que $30 \%$ a consideraram muito saborosa e $70 \%$ saborosa; ainda em seu estudo, constataram que $65 \%$ dos participantes nunca tinham ouvido falar na planta. Também, Ferreira et al. (2016) realizaram uma pesquisa com crianças em duas escolas com oficinas sobre alimentação saudável, e apresentou as PANC para as crianças, constatando que algumas conheciam; no entanto, nenhuma havia provado estas plantas. Os autores destacam que as crianças adoram a experiência. As atividades práticas e a experimentação das PANC auxiliaram a divulgar o conhecimento sobre elas, e a levar uma opção de diversidade alimentar que não era conhecida pelos alunos.

\section{Conclusão}

As ações realizadas junto com crianças em vulnerabilidade social foram efetivas na promoção e valorização das PANC e da alimentação saudável. 


\section{Referências}

AIOLFI, A. H.; BASSO, C. Preparações elaboradas com aproveitamento integral dos alimentos. Disciplinarum Scientia| Saúde, 2016.

ALVES, E. M.; CUNHA, W. A importância da agricultura orgânica na visão social e ecológica. Revista F@ pciência, 2012, 9.1: 1-7.

BIRCH, L.; SAVAGE, J.S.; VENTURA, A. Influences on the Development of Children's Eating Behaviours: From Infancy to Adolescence. Canadian Journal of Dietetic Practice Canadian Journal of Dietetic Practice and research, 2007.

BORGES, C. K. G. D.; DA SILVA, C.C. Plantas Alimentícias Não Convencionais (Panc): A Divulgação Científica Das Espécies Na Cidade De Manaus, AM. Revista Eletrônica Científica Ensino Interdisciplinar, 2018.

BRASIL. MINISTÉRIO DO DESENVOLVIMENTO SOCIAL, et al. Política Nacional de Assistência Social: versão oficial. Conselho Nacional de Assistência Social, 2004.

CANÇADO, T. C. L.; DE SOUZA, R. S; DA SILVA CARDOSO, C. B. Trabalhando o conceito de Vulnerabilidade Social. Trabalho apresentado no XIX Encontro Nacional de Estudos Populacionais, ABEP, realizado em São Pedro-SP Brasil, 2014.

CASTELO BRANCO, M.; NOGUEIRA, J. M.; DOS SANTOS, R. C. Perfil dos consumidores de hortaliças da cidade de Santo Antônio do Descoberto-GO. Embrapa Hortaliças-Artigo em periódico indexado: Horticultura Brasileira, 2006.

CASTRO, C. M.; DEVIDE A. C. P. Cultivo e Propriedades de Plantas Alimentícias não Convencionais PANC. Pesquisadores Científicos APTA - Polo Regional Vale do Paraíba Pindamonhangaba- SP, 2016.

CECANE. Manual para aplicação dos testes de aceitabilidade no Programa Nacional de Alimentação Escolar-PNAE. Santos: Universidade Federal de São Paulo, 2010.

COSTA, C. S., et al. Comportamento sedentário e consumo de alimentos ultraprocessados entre adolescentes brasileiros: Pesquisa Nacional de Saúde do Escolar (PeNSE), 2015. Cadernos de Saúde Pública, 2018.

DAROLT, M. R. Alimentos orgânicos: um guia para o consumidor consciente -2 . ed. rev., ampl. - Londrina: IAPAR, 2007.

DE ALMEIDA, E. M. P., MONTANHA, S. M., SANTANA, P. M. C., \& SOARES, L. C. B. Educação Ambiental na escola: estudo da relação entre a alimentação e a produção de resíduos. Revista Brasileira de Educação Ambiental, v.8, n.2, pp.131-149, 2013.

DE SOUZA, R. S., et al. Comportamento de compra dos consumidores de frutas, legumes e verduras na região central do Rio Grande do Sul. Ciência Rural, 2008. 
DIAS, V. D. V.; SCHULTZ, G.; SCHUSTER, M. D. S.; TALAMINI, E.; RÉVILLION, J. P. O mercado de alimentos orgânicos: um panorama quantitativo e qualitativo das publicações internacionais. Ambiente \& Sociedade, 2015.

DUTRA, R. M. S.; de SOUZA, M. M. O. Impactos negativos do uso de agrotóxicos à saúde humana. Hygeia, v.13, n.24, p.1-27, 2017.

FERREIRA, A. P., et al. Sombra, escola fresca e alimentação saudável: experiências de educação ambiental agroecológica do coletivo caipora, em Sete Lagoas, MG. In: SEMINÁRIO NACIONAL DE EDUCAÇÃO EM AGROECOLOGIA, 2., 2016, Seropédica. Educação em agroecologia: resistências e lutas pela democracia: [resumos expandidos]. Rio de Janeiro: Associação Brasileira de Agroecologia, 2016.

FONSECA, F. F., et al. As vulnerabilidades na infância e adolescência e as políticas públicas brasileiras de intervenção. Revista Paulista de Pediatria, 2013.

FRANCILINO, A. H., et al. Perfil dos consumos de hortaliças no município de Iguatu-CE. Revista Verde de Agroecologia e Desenvolvimento Sustentável, 2014.

GIL, A. C. Métodos e técnicas de pesquisa social. 6. ed. Ediitora Atlas SA, 2008.

GIRALDI, M. Recursos alimentares vegetais em duas comunidades caiçaras no sudeste do Brasil: discutindo modos de vida e segurança alimentar. $79 f$. Dissertação (Mestrado em Botânica) - UFRPE / Recife, 2012.

GOLZE, V. L. O.; SOUZA, T. A. Aceitabilidade de alimentação à base de capuchinha (Tropaeolum majus). Cadernos de Agroecologia, 2009, 3.1.

GONDIM, J. A.; MELO, et al. Composição centesimal e de minerais em cascas de frutas. Ciência e Tecnologia de Alimentos, 2005.

KELEN, M. E. B., et al. Plantas alimentícias não convencionais (PANCs): hortaliças espontâneas e nativas. UFRGS: Porto Alegre, 2015.

KINUPP, V. F.; LORENZI, H. Plantas Alimentícias Não Convencionais (PANC) no Brasil. São Paulo - SP: Instituto Plantarum de Estudo da Flora, 2014.

KINUPP, V. F.; DE BARROS, I. B. I. Riqueza de plantas alimentícias nãoconvencionais na Região Metropolitana de Porto Alegre, Rio Grande do Sul. Revista Brasileira de Biociências, 2007.

KINUPP, V. F.; DE BARROS, I. B. I. Teores de proteína e minerais de espécies nativas, potenciais hortaliças e frutas. Ciência e Tecnologia de Alimentos, 2008.

MARCONI, M. A.; LAKATOS, E. M. Técnicas de pesquisa. São Paulo: Atlas, 2002. 
NUNES, J. T. Aproveitamento integral dos alimentos: qualidade nutricional e aceitabilidade das preparações. 2009. 64f. Monografia (Especialização em Qualidade de Alimentos). Universidade de Brasília, Brasília, 2009.

OTT, A. et al. Alimentação Saudável Na Infância. 10 Simpósio de Agronomia e Tecnologia em alimentos. FAl Faculdades. 2014. Disponível em: < http://www.faifaculdades.edu.br/eventos/AGROTEC/2014/1AGROTEC/arquivos /resumos/res3.pdf> Acesso em: 12 de nov. de 2019.

PAULA FILHO, G. X. Agroecologia e recursos alimentares não convencionais: contribuições ao fortalecimento da soberania e segurança alimentar e nutricional. CAMPO-TERRITÓRIO: revista de geografia agrária, 2015.

RAIMUNDO, M. G. M (org); MACHADO, J. V. F. (coord). Diga não ao desperdício e Panc. São Paulo - Coordenadoria de Desenvolvimento dos Agronegócios, 2018.

RANIERI, G. R., et al. Guia prático sobre PANC: plantas alimentícias não convencionais. São Paulo: Instituto Kairós, 2017.

SANGALLI, A.; SCALON, S.P.Q; CARVALHO, J.C.L. Perda de Massa de Flores de Capuchinha após armazenamento. Horticultura Brasileira, Brasília, 2007.

SOUSA, M. J. R. D. Promoção da alimentação saudável em crianças em idade escolar: estudo de uma intervenção. Tese de mestrado: Universidade de Lisboa, Faculdade de Psicologia e de Ciências da Educação, 2009.

SOUZA, A. M., et al. Alimentos mais consumidos no Brasil: Inquérito nacional de alimentação 2008-2009. Revista de Saúde Pública, 2013.

SOUZA, L. B.; PANÚNCIO-PINTO, M. P.; FIORATI, R. C. Crianças e adolescentes em vulnerabilidade social: bem-estar, saúde mental e participação em educação. Cadernos Brasileiros de Terapia Ocupacional, 2019.

THIOLLENT, M. Metodologia da Pesquisa-Ação. 2a Ed. São Paulo: Editora Cortez, $1986 . \quad$ Disponível em: https://marcosfabionuva.files.wordpress.com/2018/08/7-metodologia-dapesquisa-ac3a7c3a3o.pdf. Acesso em:12 de mar. 2021.

VIEBIG, R. F., et al. Consumo de frutas e hortaliças por idosos de baixa renda na cidade de São Paulo. Revista de Saúde Pública, 2009.

VIEIRA, V. L.; FIORE, E. G.; CERVATO-MANCUSO, A. M. Insegurança alimentar em região de alta vulnerabilidade social da cidade de São Paulo. Segurança Alimentar e Nutricional, 2006.

WIGGERS, L. I. et al. Horto didático da UTFPR Campus Pato Branco: unidade demonstrativa de plantas alimentícias não convencionais. Cadernos de Agroecologia - Anais do VI CLAA, X CBA e V SEMDF, v. 13, n. 1, 2018. 


\section{ANEXO A - QUESTIONÁRIO - PREFERÊNCIA ALIMENTAR}

Nome:

Idade:

1) Marque as refeições que você faz durante o dia.

( ) café da manhã ( ) Lanche da manhã ( ) Almoço ( ) lanche da tarde ( ) janta ( ) ceia

2) Como costuma ser seu café da manhã?

a) Café preto e pão;

b) Café com leite, pão branco, margarina, queijo e presunto;

c) Frutas e sucos naturais, cereais integrais, tapioca, pão integral.

d) outros

3) Qual é, em média, a quantidade de frutas que você consome por dia?

a) Não como frutas nem bebo suco natural c) Duas ou menos unidades.

de frutas todos os dias; d) Duas ou menos vezes por semana

b) Três unidades; e) outros

4) Quais frutas você gosta de comer?

5) O que você leva de lanche para a escola?

a) Não levo nenhum tipo de lanche; c)

b) Chocolates, pães, bolachas recheadas, sanduíche.

salgadinhos, refrigerante; d) outros

6) Você consome algum tipo de verdura ou legume todos os dias:

( ) Não consumo verdura nem legumes; ( ) Duas ou menos vezes por semana;

( ) Todos os dias.

7) Quais verduras e legumes você gosta de comer?

8) Você costuma tomar refrigerantes com qual frequência?

( ) Não tomo refrigerantes; ( ) Três ou menos vezes por semana; ( )Todos os dias.

9) Você come lanches como: xis e cachorro quente? Com que frequência?

( ) Não como; ( ) Duas ou menos vezes por semana; ( ) Todos os dias.

10) Você conhece Plantas Alimentícias Não Convencionais (PANC)?
( ) Sim
( ) Não
( ) Talvez

13) Se sim, quais você costumar comer?

14) Todas as plantas que existem podemos comer?
( ) Sim
( ) Não

15) Você já comeu alguma destas plantas?
( ) Capuchinha
( ) Folha de batata doce
( ) Ora-pro-nobis
( ) Peixinho de jardim
( ) Coração de bananeira

16) Você já comeu alguma flor comestível? Ou já ouviu falar em flores comestíveis?
( ) $\operatorname{Sim}$
( ) Não
( ) Talvez

17) $O$ que é alimentação saudável para você?

18) $O$ que é uma alimentação orgânica? 